\title{
A Coupled Modeling Study of the Seasonal Cycle of the Pacific Cold Tongue. Part I: Simulation and Sensitivity Experiments
}

\author{
Xiouhua Fu AND Bin Wang \\ Department of Meteorology and International Pacific Research Center, * School of Ocean and Earth Science and Technology, \\ University of Hawaii at Manoa, Honolulu, Hawaii
}

(Manuscript received 22 November 1999, in final form 18 January 2000)

\section{ABSTRACT}

\begin{abstract}
A coupled tropical ocean-atmosphere model that fills the gap between anomalous coupled models and fully coupled general circulation models is described. Both the atmosphere and ocean are represented by two and one-half layer primitive equation models, which accentuate the physical processes in the oceanic mixed layer and atmospheric boundary layer. The two media are coupled through both momentum and heat flux exchanges without explicit flux correction. The coupled model, driven by solar radiation, reproduces realistic seasonal cycles of the mixed layer temperature, currents, and depth, and the surface winds and rainfall in the tropical Pacific.

The model results indicate that the equatorial westward phase propagation of the annual warming is primarily caused by zonal temperature advection and downward solar radiation modified by clouds, whereas the windevaporation-SST feedback plays a minor role. The meridional wind component appears to have a stronger impact than the zonal wind component on the seasonal cycle of the eastern Pacific cold tongue, because the cross equatorial winds have stronger annual variation, which is more effective in regulation of SST through changing surface evaporation and mixed layer entrainment. The annual variation of the solar forcing is shown to have a significant impact on the long-term mean state. Without the seasonal cycle forcing, the western Pacific warm pool would shift eastward and the latitudinal climate asymmetry in the eastern Pacific would be stronger.
\end{abstract}

\section{Introduction}

Near the equator, the semiannual harmonic component of the solar radiation at the top of the atmosphere exceeds that of the annual harmonic by $20 \%$ (Wang 1994). However, the annual variation of the SST in the equatorial eastern Pacific is overwhelmed by the annual cycle with a warm season occurring in boreal spring and a cold season in boreal fall (Wyrtki 1965; Horel 1982; Mitchell and Wallace 1992). The annual maximum (minimum) of SST in the region of the cold tongue displays distinct westward and northward phase propagation (Wyrtki 1965). The annual warming (cooling) exhibits similar propagation (Horel 1982; Wang 1994).

The equatorial westward propagation of the annual warming is accompanied by westward propagation of the surface zonal wind. Horel (1982) applied Bjerknes's (1969) concept of zonal wind-upwelling-SST feedback

\footnotetext{
* The International Pacific Research Center is partly sponsored by the Frontier Research System for Global Change.

Corresponding author address: Dr. Bin Wang, Department of Meteorology, University of Hawaii, 2525 Correa Road, Honolulu, HI 96822.
}

to explain the westward propagation. On the other hand, Mitchell and Wallace (1992) noticed that the cross-equatorial flow exhibits a much more robust signal of annual variation then the equatorial zonal wind component. They hypothesized a positive feedback between the cross-equatorial winds and meridional SST gradients, which may play a critical role in the annual evolution of the eastern Pacific cold tongue (EPCT). The analysis of Wang (1994) revealed that although the local solar radiation is dominated by a semiannual component, the antisymmetric solar forcing (the contrast in solar radiative forcing between the Northern and Southern Hemispheres) plays an important role in determining the seasonal cycle of the EPCT. This is because the antisymmetric solar forcing induces a significant annual variation in the trade wind system that regulates the equatorial atmosphere-ocean interaction. For instance, the annual march of the intertropical convergence zone (ITCZ) is, to a large extent, driven by annual variation of the trades. When the ITCZ is closest to the equator in February and March, both the zonal and meridional wind speeds at the equator reach an annual minimum, causing spring warming of the cold tongue. Therefore, the physical processes determining the seasonal cycle of the EPCT include not only a local air-sea interaction but also an interaction between the Tropics and extra- 
tropics regulated by the antisymmetric solar forcing. In fact, the seasonal cycle of the EPCT closely follows the seasonal cycle of SST in the Southern Hemisphere with a phase delay of one or two months (Wang and Wang 1999).

A number of simple anomaly air-sea coupled models have been developed to describe this system. These models have identified and emphasized the important roles of three processes of air-sea interaction in the seasonal cycle of the EPCT: wind-evaporation-SST feedback, zonal wind-upwelling-SST feedback, and stratocumulus cloud-radiation-SST feedback (Xie 1994; Liu and Xie 1994; Liu 1996; Chang and Philander 1994; Chang 1996; Li and Philander 1996). These models have qualitatively demonstrated how the air-sea interactions affect the annual variation of the tropical Pacific. However, these simple models assumed a constant mixed layer (ML) depth. This assumption may be problematic in a study of the seasonal cycle, because the mixed layer depth variation plays a critical role in the seasonal cycle of SST in the equatorial eastern Pacific (Chen et al. 1994). In addition, these models describe only the annual departures from a specified annual mean, and thus are unable to account for the interactions between the seasonal cycle and climatological mean. The rectification of the seasonal cycle to the mean state was shown to be nonnegligible (Wang and Wang 1999). Due to the simplicities of these models, quantitative assessment of the contribution of various processes has to rely on more sophisticated models.

Efforts have been made to diagnose the principal processes responsible for the annual variation of SST in the cold tongue using observations and ocean general circulation models (Swenson and Hansen 1999; Kessler et al. 1998). Undoubtedly, both the above approaches contribute a lot to the progress in our understanding of this issue. However, the availability and uncertainty of data largely limit the observational approach. For the stand-alone ocean modeling approach, the major difficulties lie in two aspects: the effect of negative feedback through using the external boundary forcing is unknown (Neelin et al. 1992); the possible distortion of the physics due to errors in the forcing fields is unknown. Therefore, use of coupled models is desirable for a quantitative assessment of the importance of the various processes in the seasonal cycle of SST, provided the coupled model can reproduce realistic seasonal cycles in both the ocean and the atmosphere.

The present coupled general circulation models (CGCMs) have a certain degree of difficulty in reproducing the seasonal cycle in the tropical Pacific (Mechoso et al. 1995), though some of them (Robertson et al. 1995; Yu and Mechoso 1999) have been used to study the seasonal cycle of the cold tongue. Due to the complexity of the model physics and computational limitations, it is also difficult to perform a large number of numerical experiments in order to test various hypotheses concerning the mechanisms. For this reason, we have developed a coupled model with intermediate com- plexity. This model includes complete thermodynamics of the ocean mixed layer and the dynamics of the upper ocean that are necessary for realistic computation of SST. The computational efficiency of the model (normally two orders of magnitude faster than CGCMs) allows a large number of experiments to be performed.

In Part I (the present paper) we first describe the formulation of the coupled model. The performance and adequacy of the coupled model for studying the annual cycle of the tropical Pacific is evaluated in section 3. The intermediate coupled model will then be used to investigate the mechanism of equatorial westward progression of the annual warming (section 4). Numerical experiments are also performed to assess the impacts of the annual cycle on the formation of the long-term mean state of the tropical Pacific and to estimate the relative importance of the equatorial zonal wind versus crossequatorial wind in the seasonal cycle of the EPCT (section 5). The last section summarizes our results.

\section{The intermediate coupled ocean-atmosphere model}

\section{a. The atmospheric model}

The atmospheric model is a two and one-half layer primitive equation model on the equatorial beta-plane originally developed by Wang and Li (1993) and improved by Fu and Wang (1999) (hereafter WLF model). The vertical structure of the atmospheric model is shown in Fig. 1. Here, we briefly summarize the essential features of the model physics. The model describes heatinginduced free tropospheric flows (the lowest baroclinic mode) and SST gradient-forced boundary layer flows, as well as their interaction. In the parameterization of convective heating, the large-scale convective instability is assumed to be a function of the surface temperature based on the empirical relation between the probability of deep convection occurrence and total SST in the Tropics (Waliser et al. 1993). The model also includes the effects of cloud-longwave radiation and boundary layer thermodynamics on the surface winds. The low-level clouds in the eastern Pacific cause strong longwave radiational cooling, whereas the deep convective clouds in the western Pacific tend to trap outgoing longwave radiation. The horizontal differential cloud-radiative forcing has significant impacts on the tropical surface winds (Fu and Wang 1999). Fu and Wang have also shown that in the vicinity of the equator, the vertical temperature advection in the boundary layer is important for improving simulated surface wind divergence. Because the computation of surface air humidity is critical to calculation of the surface latent heat flux, a bulk moisture balance equation was used in the model boundary layer to explicitly compute air humidity. The simulated tropical surface air humidity compares favorably with available observations.

In the free troposphere, the governing equations for the gravest baroclinic mode are 

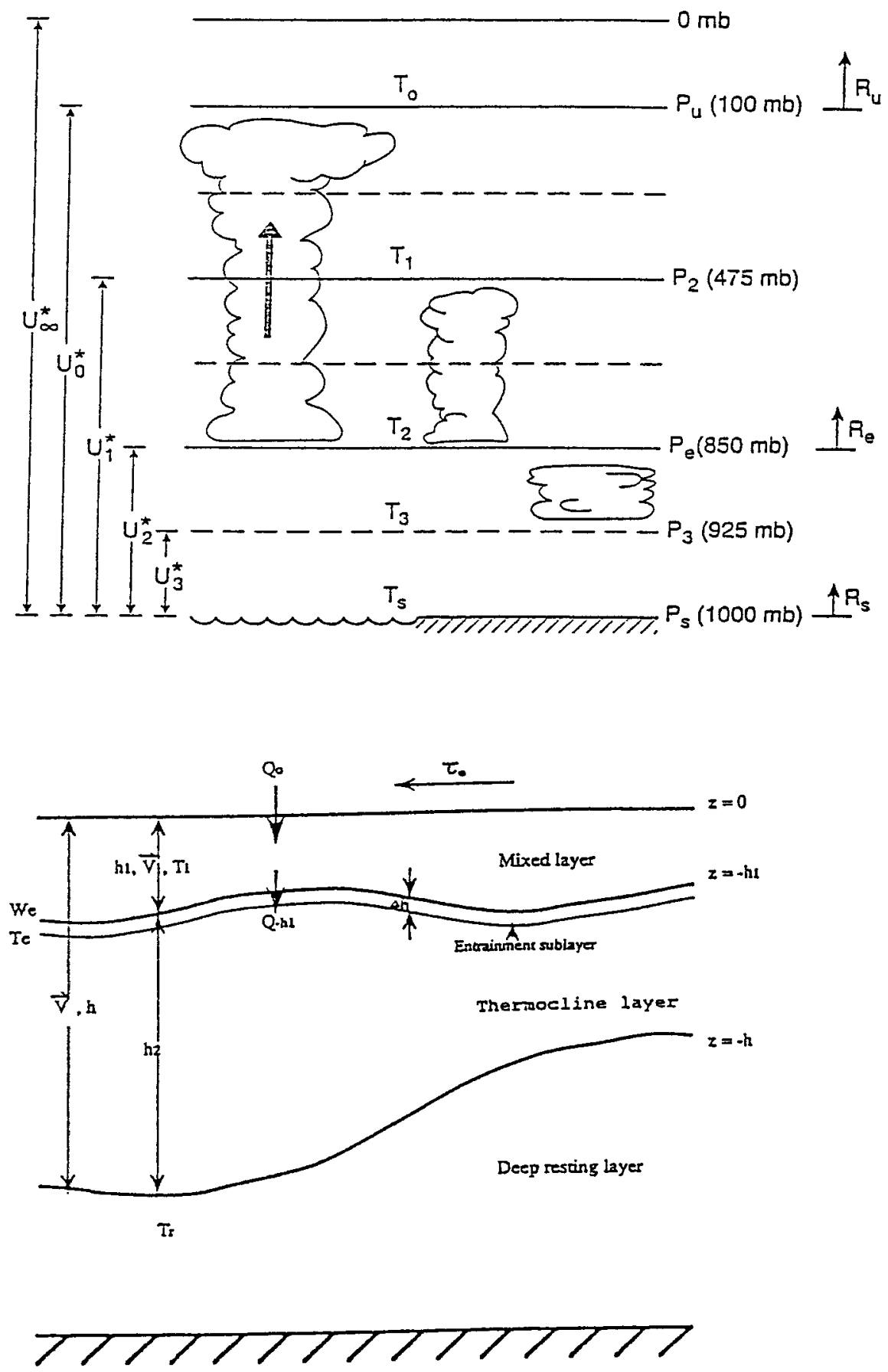

FIG. 1. Schematic vertical structure of the coupled ocean-atmosphere model.

$$
\begin{aligned}
& \frac{\partial \mathbf{V}}{\partial t}+\beta y k \times \mathbf{V}=-\nabla \Phi-\varepsilon \mathbf{V}+K_{H} \nabla^{2} \mathbf{V}, \\
& \frac{\partial \Phi}{\partial t}+\frac{S_{2} \Delta p}{2} \omega_{2}=-\frac{R \Delta p}{2 C_{p} p_{2}}\left(Q_{p 2}+Q_{r 2}\right)+K_{H} \nabla^{2} \Phi,
\end{aligned}
$$

and

$$
\omega_{2}=\omega_{e}+\Delta p \nabla \cdot \mathbf{V}
$$

where $\mathbf{V}$ and $\Phi$ represent, respectively, the horizontal velocity and geopotential in the lower free troposphere; $\omega_{2}$ is the vertical pressure velocity at the middle of the free troposphere. Also, $Q_{p 2}$ and $Q_{r 2}$ denote the heating rate due to precipitation and longwave radiation, respectively. The schemes used to calculate $Q_{p 2}$ and $Q_{r 2}$ are presented in detail in Wang and Li (1993) and in Fu and Wang (1999), respectively.

In the boundary layer, 


$$
\begin{aligned}
\frac{\partial \mathbf{V}_{B}}{\partial t}+\beta y k \times \mathbf{V}_{B}= & -\nabla \Phi_{B}-\varepsilon_{B} \mathbf{V}_{B}+K_{H} \nabla^{2} \mathbf{V}_{B}, \\
\frac{\partial q_{B}}{\partial t}+\frac{\omega_{e} \Delta q_{B}}{2\left(p_{s}-p_{e}\right)}= & \frac{m_{a} C_{E}\left|\mathbf{V}_{B}\right|\left(q_{s}-\mu_{q} q_{B}\right)}{p_{s}-p_{e}} \\
& +K_{H} \nabla^{2} q_{B}, \\
\frac{\partial \Phi_{d}}{\partial t}+\left(p_{s}-p_{e}\right) \frac{S_{b} \omega_{e}}{2}= & \frac{R \rho g}{p_{3}} F_{T_{S}}-\frac{R\left(p_{s}-p_{e}\right)}{p_{3} C_{p}} Q_{r B} \\
& +K_{H} \nabla^{2} \Phi_{d}, \text { and } \\
\omega_{e}= & \left(p_{s}-p_{e}\right) \nabla \cdot \mathbf{V}_{B},
\end{aligned}
$$

where $\mathbf{V}_{B}$ and $\Phi_{B}$ represent the horizontal velocity and geopotential in the boundary layer, respectively; $q_{B}$ and $\Phi_{d}$ denote the air humidity and geopotential thickness of the boundary layer; $q_{s}$ represents the saturation specific humidity, which is calculated with the ClausiusClapeyron equation; $\omega_{e}$ is the vertical pressure velocity at the top of the boundary layer; $\varepsilon_{B}$ denotes the surface friction coefficient and is defined as $\left(\left|\mathbf{V}_{B}\right|^{1.5} / H_{i} \times 10^{-3}\right)$, where $H_{i}$ is the depth of the friction layer $(1000 \mathrm{~m}$ in this model); $p_{3}$ the pressure at the middle of the boundary layer $=\left(p_{e}+p_{s}\right) / 2 ; m_{a}$ in (5) represents the surface moisture availability; $F_{T S}$ the surface sensible heat flux; $Q_{r B}$ is longwave radiation heating rate in the boundary layer. The detailed schemes for computing $m_{a}, F_{T s}$, and $Q_{r B}$ are presented in Fu and Wang (1999). The parameter values used for the atmospheric model are as follows: $\varepsilon=5 \times 10^{-6} \mathrm{~s}^{-1}, S_{2}=3.33 \times 10^{-6} \mathrm{~m}^{2} \mathrm{~s}^{-2} P_{a}^{-2}, K_{H}$ $=2.5 \times 10^{5} \mathrm{~m}^{2} \mathrm{~s}^{-1}, \Delta p=375 \mathrm{mb}, S_{b}=0.87 \times 10^{-6}$ $\mathrm{m}^{2} \mathrm{~s}^{-2} P_{a}^{-2}, p_{s}=1000 \mathrm{mb}, p_{e}=850 \mathrm{mb}, p_{2}=475 \mathrm{mb}$, $\mu_{q}=0.25, C_{E}=1.5 \times 10^{-3}$.

The model atmosphere covers the global Tropics between $30^{\circ} \mathrm{S}$ and $30^{\circ} \mathrm{N}$. The horizontal resolution is $2^{\circ}$ lat $\times 4^{\circ}$ long. In order to maintain the computational stability, a simulated backward scheme (Matsuno 1966) is used with a time increment of $30 \mathrm{~min}$. Radiational boundary conditions (Miller and Thorpe 1981) are used at the north and south boundaries to eliminate artificial wave reflection. Fu (1998) has documented the model's performance in simulating both the tropical climatology and interannual variations of the surface winds, sea level pressure (SLP), air humidity, and rainfall in detail.

\section{b. The ocean model}

The ocean model is an improved version of Wang et al. (1995). Its vertical structure is presented in Fig. 1. This model comprises an ML, in which the temperature and velocity are vertically uniform, and a thermocline layer in which temperature decreases linearly from the mixed-layer base to the thermocline base. Both layers have variable depths. The deep ocean beneath the thermocline base is motionless with a constant reference temperature. The entrained water temperature is parameterized in terms of the vertical temperature gradient between the mixed layer and the deep inert layers. The mixed-layer turbulence parameterization follows that of Gaspar (1988), which treats the penetrated solar radiation in a more realistic fashion. The momentum equations for the mixed layer and the thermocline layers follow those of McCreary and Yu (1992). Fu (1998) has evaluated the performance of the model in detail.

The governing equations for the mixed layer are

$$
\begin{aligned}
& \quad \frac{\partial h_{1}}{\partial t}+\boldsymbol{\nabla} \cdot\left(h_{1} \mathbf{V}_{1}\right)=W_{e}+W_{d}+v \nabla^{2}\left(h_{1}\right) \\
& \frac{\partial}{\partial t}\left(h_{1} \mathbf{V}_{1}\right)+\boldsymbol{\nabla} \cdot\left(\mathbf{V}_{1} h_{1} \mathbf{V}_{1}\right)+f k \times h_{1} \mathbf{V}_{1}+h_{1}\left\langle\nabla p_{m 1}\right\rangle \\
& =\tau_{s}+W_{e} \mathbf{V}_{2}+W_{d} \mathbf{V}_{1}+v \nabla^{2}\left(h_{1} \mathbf{V}_{1}\right), \quad \text { and } \\
& \frac{\partial T_{1}}{\partial t}+\mathbf{V}_{1} \cdot \boldsymbol{\nabla} T_{1} \\
& =-\frac{W_{e}}{h_{1}} H\left(W_{e}\right)\left(T_{1}-T_{e}\right)+\frac{Q_{0}-Q_{h 1}}{\rho_{r} c_{w} h_{1}}+v \nabla^{2} T
\end{aligned}
$$

In the thermocline layer:

$$
\begin{gathered}
\frac{\partial h_{2}}{\partial t}+\boldsymbol{\nabla} \cdot\left(h_{2} \mathbf{V}_{2}\right)=-W_{e}-W_{d}+v \nabla^{2}\left(h_{2}\right) \\
\frac{\partial}{\partial t}\left(h_{2} \mathbf{V}_{2}\right)+\boldsymbol{\nabla} \cdot\left(\mathbf{V}_{2} h_{2} \mathbf{V}_{2}\right)+f k \times h_{2} \mathbf{V}_{2}+h_{2}\left\langle\boldsymbol{\nabla} p_{t l}\right\rangle \\
=-W_{e} \mathbf{V}_{2}-W_{d} \mathbf{V}_{1}+v \nabla^{2}\left(h_{2} \mathbf{V}_{2}\right)
\end{gathered}
$$

In Eqs. (8)-(12), $\mathbf{V}_{i}$ and $h_{i}$ are, respectively, the current and thickness for the ML $(i=1)$ and thermocline layer $(i=2)$. Here, $\boldsymbol{\tau}_{s}$ denotes the wind stress at the surface, and $v$ is the horizontal diffusion coefficient; $Q_{o}$ and $Q_{h 1}$ are downward fluxes at the surface and the ML base (or the penetrated solar radiation), respectively. The horizontal pressure gradients in each layer are given by (McCreary and Yu 1992)

$$
\begin{aligned}
\left\langle\nabla p_{m 1}\right\rangle= & \alpha g \nabla\left[h_{1}\left(T_{1}-T_{r}\right)+h_{1}\left(T_{t 1}-T_{r}\right)\right] \\
& -\alpha g h_{1} \nabla T_{1} / 2 \text { and } \\
\left\langle\nabla p_{t 1}\right\rangle= & \alpha g \nabla\left[\left(h_{1}+h_{2}\right)\left(T_{t 1}-T_{r}\right)\right] \\
& -\alpha g\left(h_{1}+h_{2} / 2\right) \nabla T_{t 1},
\end{aligned}
$$

where $\alpha$ is the coefficient of thermal expansion; $T_{1}, T_{t 1}$ $=\left(T_{1}+T_{r}\right) / 2$, and $T_{r}$ are the mean temperature of the mixed-layer, thermocline-layer, and quiescent deep ocean, respectively.

The entrainment rate $W_{e}$ is calculated with (Gaspar 1988)

$$
\begin{array}{rl}
W_{e} & H\left(W_{e}\right) \alpha g h_{1}\left(T_{1}-T_{e}\right) \\
= & 2 m_{s} u_{*}^{3} \\
& -h_{1}\left[\left(1+m_{b}\right) B\left(h_{1}\right)+\left(1-m_{b}\right)\left|B\left(h_{1}\right)\right|\right] / 2,
\end{array}
$$


TABLE 1. The major parameter values used in the ocean model.

\begin{tabular}{lll}
\hline \hline$T_{r}$ & Reference deep-water temperature & $10^{\circ} \mathrm{C}$ \\
$R_{p}$ & Solar radiation penetration coefficient & 0.60 \\
$\gamma$ & Attenuation coefficient of the penetrated solar & 0.05 \\
$\quad \quad$ radiation \\
$C_{D}$ & Momentum exchange coefficient & $1.3 \times 10^{-3}$ \\
$m_{s}$ & Turbulent mixing coefficient due to wind stir- & $1.25-0.4$ \\
$\quad$ & $\quad$ ring \\
$m_{b}$ & Turbulent mixing coefficient due to convection & 0.2 \\
$\Delta h_{e}$ & Thickness of the entrainment layer & $4.5 \mathrm{~m}^{-1}$ \\
$v$ & Horizontal turbulent momentum and heat diffu- & $10^{4} \mathrm{~m}^{2} \mathrm{~s}^{-1}$ \\
& $\quad$ sion coefficient \\
\hline
\end{tabular}

$$
\begin{aligned}
B\left(h_{1}\right)=-\frac{\alpha g}{\rho c_{w}}\{ & Q_{0}+\left(1-R_{p}\right) F_{s w} \\
& \left.\times\left[e^{-\gamma h 1}-\frac{2}{\gamma h_{1}}\left(1-e^{-\gamma h 1}\right)\right]\right\},
\end{aligned}
$$

where $u_{*}$ is surface friction velocity; the parameters $m_{s}$ and $m_{b}$ are turbulent mixing factors due to wind stirring and convection, respectively. Here, $R_{p}$ and $\gamma$ denote the solar radiation penetration coefficient and the attenuation coefficient of the penetrated solar radiation. Also, $F_{s w}$ is the downward solar radiation flux at the ocean surface. The entrained water temperature $\left(T_{e}\right)$ is estimated by the mean vertical temperature gradient in the thermocline layer $\left(h_{2}\right)$

$$
T_{1}-T_{e}=\Delta h_{e} \frac{T_{1}-T_{r}}{h_{2}},
$$

where $\Delta h_{e}$ is a given thickness of an entrainment layer. If the right-hand side of (15) is negative, the detrainment rate $W_{d}$ is estimated by

$$
W_{d}=\frac{h_{1}-h_{r}}{\Delta t},
$$

where $h_{r}$ is an equilibrium mixed-layer depth with the right-hand side of (15) equal to zero; $\Delta t$ is the time step of the ocean model.

The major parameter values of the ocean model used in the control run are listed in Table 1. The schemes to estimate $\boldsymbol{\tau}_{s}, Q_{o}, Q_{h 1}$, and $F_{s w}$ are given in detail by Wang et al. (1995). The ocean model extends from $120^{\circ} \mathrm{E}$ to $80^{\circ} \mathrm{W}$, and from $30^{\circ} \mathrm{S}$ to $30^{\circ} \mathrm{N}$ with realistic but simplified eastern and western boundaries of the Pacific Ocean. The standard spatial resolution of the model is $1^{\circ}$ lat $\times 2^{\circ}$ long, which requires an approximate time interval of $3 \mathrm{~h}$. No-flux conditions for temperature and free-slip conditions for velocities are applied at the coastal boundaries. To minimize the artificial effect of the northern and southern boundaries, the model temperature is relaxed back to the seasonally varying climatology derived from the Comprehensive Ocean-Atmosphere Data Set (COADS). The relaxation time is a function of latitude only and increases exponentially from the north and south boundaries $\left(30^{\circ} \mathrm{S}\right.$ and $\left.30^{\circ} \mathrm{N}\right)$ to the equator as

$$
\mathrm{RT}(\text { day })=0.5 /\left[e^{(-d s / 1.5)}+e^{(-d n / 1.5)}\right]
$$

where RT(day) represents the relaxation time in unit of day; the $d s$ and $d n$ denote the absolute distance ( ${ }^{\circ}$ latitude) from the north and south boundaries, respectively. The relaxation time in the model is about one-half day at the boundaries, 200 days near $20^{\circ} \mathrm{S}$ (and $20^{\circ} \mathrm{N}$ ), and 440 years near $10^{\circ} \mathrm{S}$ (and $10^{\circ} \mathrm{N}$ ).

\section{c. The coupling scheme}

A global tropical atmosphere model is coupled with a tropical Pacific Ocean model. Outside the tropical Pacific, the underlying sea surface temperature is specified as the climatological monthly means taken from a blended dataset of observations by buoys, ships, and satellites constructed by Reynolds (1988). Over land, the surface temperature is specified using 1000-mb air temperature from ECMWF 9-yr (1985-93) climatological monthly means. The cloud data are climatological means from the ISCCP C2 dataset (Rossow et al. 1988). Over the tropical Pacific region, the ocean-atmosphere is fully coupled except with specified clouds. The cloud-radiation interaction in the coupled system (including the parameterization of clouds in GCMs) is complex and our understanding is far from sophisticated (Slingo and Slingo 1988; Philander et al. 1996; Schneider et al. 1997). Therefore, our strategy is to specify cloud amounts in computing atmospheric longwave radiation and the downward shortwave radiation at the ocean surface.

In this coupled model, the atmospheric component exchanges information with the ocean component once per day. The atmosphere provides daily mean surface winds and heat fluxes to the ocean model. The latter send daily mean SST back to the former. The coupled model is integrated for $10 \mathrm{yr}$, with seasonally varying solar radiation forcing and cloudiness. The initial atmospheric field is the perpetual steady response to the fixed SST at 1 January (interpolating from the monthly means in December and January) obtained with the stand-alone atmospheric model. The initial ocean field is established in a similar way. After a 6-yr integration, SST approaches a steady annual cycle. The last 4-yr simulation is used to construct the model climatological mean annual cycle.

\section{Simulated tropical Pacific climate}

\section{a. The annual mean fields}

The simulated annual mean SST shows a realistic eastern Pacific cold tongue, a western Pacific warm pool, and the warm water under the ITCZ (Fig. 2a). The errors in SST are generally less than $1^{\circ} \mathrm{C}$ except for the excessively warm areas in the western North Pacific and the southeastern Pacific along $15^{\circ} \mathrm{S}$ (Fig. 2b). These excessive warm areas in the western Pacific reflect an eastward extension of the warm pool water in off-equatorial 
(a) Mean SST(CTL)

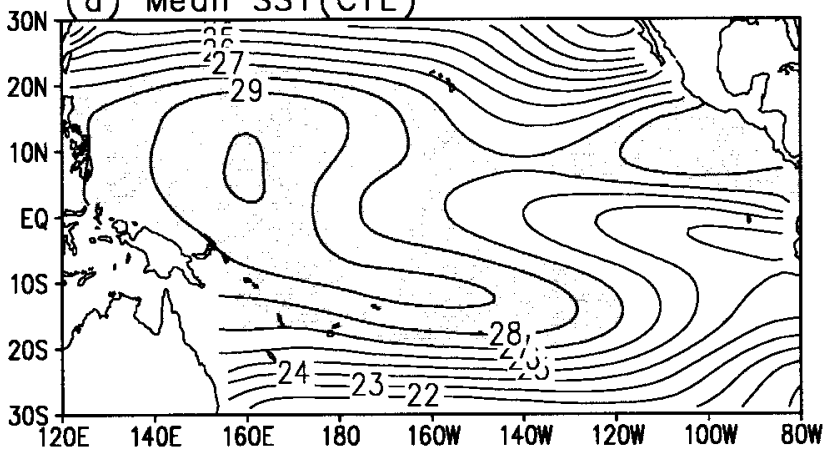

(b) SST Difference (CTL-OBS)

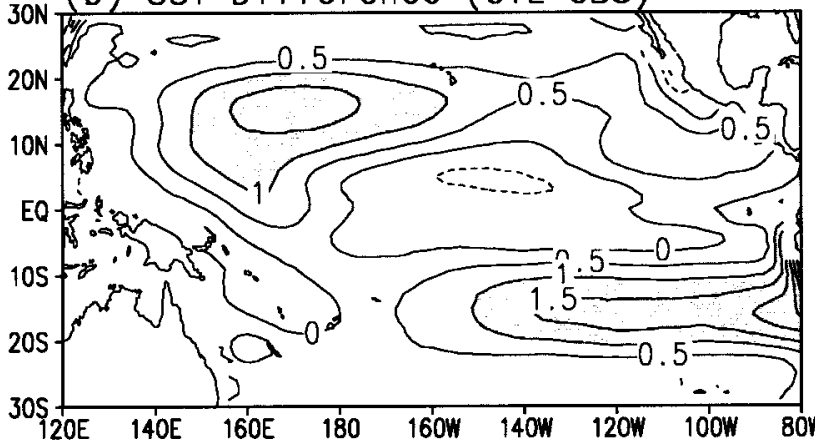

(c) Mean Surface Winds (CTL) $-8 \mathrm{~m} / \mathrm{s}$

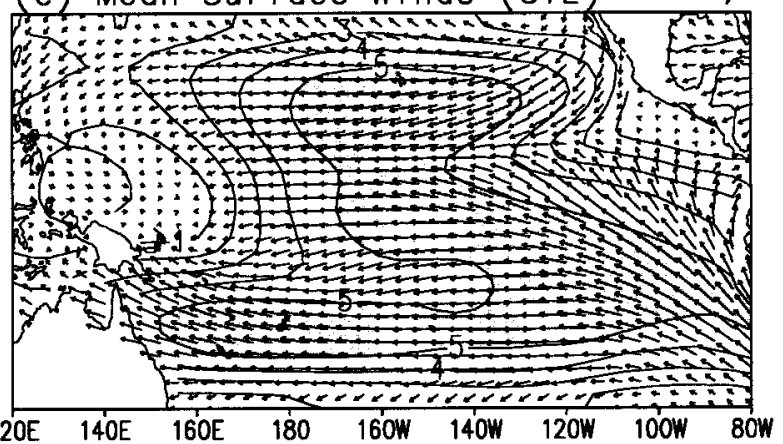

FIG. 2. (a) The simulated annual mean SST in the tropical Pacific, (b) the differences of the annual mean SST between the control run and the observations (CTL - OBS). (c) The simulated annual mean surface winds in the tropical Pacific, (d) the differences of the annual mean surface winds between the control run and the observations (CTL - OBS). The observed SST and surface winds are derived from COADS (Sadler et al. 1987).

regions. The eastward extension of warm water in the Southern Hemisphere is a common problem with the coupled GCMs (Mechoso et al. 1995). This bias appears to be associated with the coarse horizontal resolution and weak southeast trades, which result in weak coastal upwelling near the South American coast and weak westward cold advection (Fig. 2d). The surface winds are well simulated (Fig. 2c), but the easterlies are weak over the western North Pacific, particularly in the Philippine Sea (Fig. 2d), which is consistent with the warm SST bias to its east.

The annual mean SST and surface zonal winds along the equator are critical to the coupled ENSO modes, because the equatorial zonal winds determine the strength of the mean upwelling and the thermocline slope. The simulated zonal SST gradients and the easterly trades in the equatorial eastern-central Pacific follow observations closely (Fig. 3).

The annual mean mixed-layer depth simulated by the model (Fig. 4a) resembles the observations presented in Wang et al. (1995) especially the shallow mixed-layer depth (less than $30 \mathrm{~m}$ ) in the equatorial eastern Pacific. The simulated annual mean thermocline depth shows two maxima located in the subtropical northwestern and southwestern Pacific (Fig. 4b). A thermocline trough is found along the equator in consistence with the Equa- torial Undercurrent (EUC) in the model thermocline layer.

The simulated South Equatorial Current (SEC) in the mixed layer has a typical magnitude of $20-25 \mathrm{~cm} \mathrm{~s}^{-1}$ in the central-eastern equatorial region (Fig. 4a). This is comparable with the observations (Reverdin et al. 1994). The SEC is slightly stronger off the equator because strong upward entrainment of eastward momentum from the EUC had reduced its strength at the equator. The modeled SEC has a significant poleward divergent component. The mean North Equatorial Countercurrent is absent in this coupled model due to the weakness of the modeled wind stress curl over the model ITCZ (figure not shown) and the coarse meridional resolution (Schneider et al. 1997). The intense eastward currents along the equator in the thermocline layer cross the entire basin (Fig. 4b), which is the model EUC. The undercurrent core is right on the equator with a maximum speed of $65 \mathrm{~cm} \mathrm{~s}^{-1}$ at $150^{\circ} \mathrm{W}$. The undercurrent is convergent and directed upslope of the thermocline along the equator. The simulated EUC is a little weak comparing with the TAO observations (Chen et al. 1994; $\mathrm{Yu}$ and McPhaden 1999). The possible cause is the weak midlatitude circulation cell in the intermediate tropical ocean model (McCreary and Yu 1992). The inclusion of salinity and the extension of the model lateral bound- 
(a) Mean Equtorial SST (c)

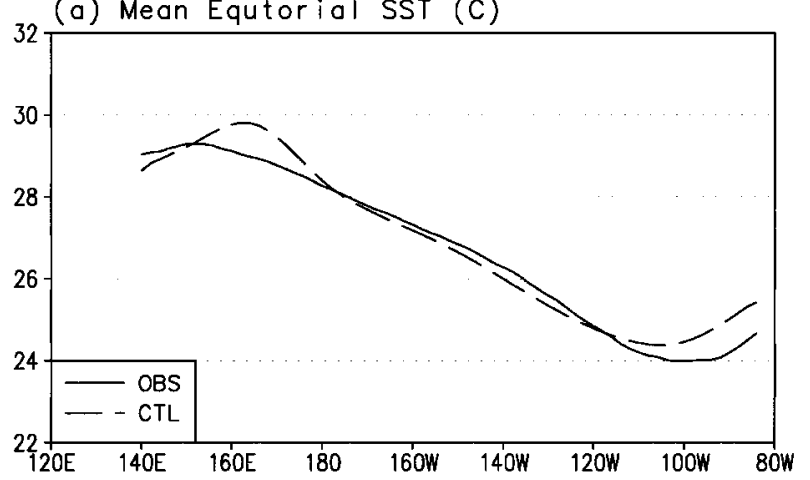

(b) Mean Equtorial Zonal Wind ( $\mathrm{m} / \mathrm{s})$

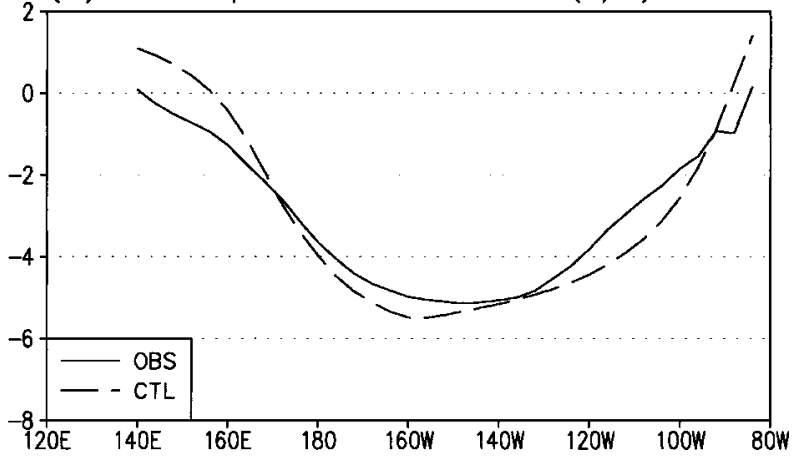

FIG. 3. (a) The annual mean equatorial Pacific SST and (b) zonal winds derived from COADS (solid lines) and simulated by the coupled model in the control run (dashed)

aries to higher latitude may improve the simulation of the EUC. Outside the equatorial waveguide, the mean currents of the thermocline layer are in geostrophic balance with pressure gradient forces, as implied by the thermocline topography.

A large entrainment rate occurs in the equatorial region with a maximum entrainment rate of $2.5 \mathrm{~m} \mathrm{day}^{-1}$ appearing in the equatorial central Pacific around $160^{\circ} \mathrm{W}$ (Fig. 4c). Entrainment also occurs along the coast of South America. In the off-equatorial regions of the western and central Pacific, detrainment is weak.

\section{b. The seasonal cycle}

Figures $5 \mathrm{a}$ and $5 \mathrm{~b}$ compare the observed and simulated seasonal cycles of SST along the equator. In the eastern Pacific, SST variation is dominated by an annual harmonic. The largest annual range $\left(\sim 4^{\circ} \mathrm{C}\right)$ occurs just east of $100^{\circ} \mathrm{W}$, where the warmest (coldest) SST appears in April (September and October), lagging the observations by one month, especially the warmest phase. The asymmetry in SST annual perturbations is captured, that is, the magnitude in the warm phase is larger than that in the cold phase. The westward progression of the annual warming is well simulated, although the simulated westward decrease of magnitude of the annual cooling is slightly slower than the observed. In the west- ern Pacific, SST shows two warm (cold) peaks in May (February) and November (August), which follow the peaks in the semiannual solar radiation forcing. The simulated large semiannual variation near the date line is exaggerated. The cause is not clear, but may be related to the inappropriate simulation of oceanic monsoons in the western Pacific.

The simulated annual variation of the equatorial zonal wind is excessively strong in the western Pacific (Figs. $5 \mathrm{c}, \mathrm{d})$, but the phase associated with the annual variation of the Asian-Australian monsoon is realistic. Over the eastern Pacific between $90^{\circ}$ and $140^{\circ} \mathrm{W}$, the westward progression of annual weakening of the trades is well captured. The largest phase discrepancies are found in the central $\left(180^{\circ}-140^{\circ} \mathrm{W}\right)$ and the far-eastern $\left(90^{\circ}-\right.$ $\left.70^{\circ} \mathrm{W}\right)$ Pacific.

In order to analyze the processes determining the equatorial SST seasonal cycle in the model, the performances of the related dynamical fields are further evaluated. Figure $6 a$ indicates that the annual variation of the ML zonal currents resembles that observed by drifting buoys and current meters (Fig. 12 in Reverdin et al. 1994). In the western Pacific, the annual reversal of zonal winds reverses the zonal currents from eastward to westward in early summer then back to eastward in October. In the central-eastern Pacific, the westward currents, driven by the easterly trades, dominate from June to the following March. The maximum $\left(50 \mathrm{~cm} \mathrm{~s}^{-1}\right)$ occurs in September. The Equatorial Undercurrent surfaces during January in the far eastern Pacific, then the eastward surface currents tend to intensify and shift westward. The maximum eastward current in the mixed layer occurs in April around $120^{\circ} \mathrm{W}$, which lags observation by about one month (Fig. 12, Reverdin et al. 1994). As opposed to the situation in the western Pacific, the reversal of the surface westward current occurring in the central-eastern Pacific is due to the ocean dynamic adjustment associated with the annual weakening of the trades in boreal spring. The annual variations of thermocline-layer zonal currents (Fig. 6b) indicate that the model EUC intensifies from the western Pacific, approaches a maximum around $150^{\circ} \mathrm{W}$, then decay eastward. In the eastern Pacific, the maximum EUC occurs in late boreal spring, which is qualitatively consistent with the observations of Kessler et al. (1998). The reversal of the zonal flow in late fall is due to the intensification of the SEC and the shallowness of the thermocline.

The annual variation of the entrainment rate on the equator is presented in Fig. 6c. In the eastern Pacific, due to weak winds and large downward solar radiation in early spring, the entrainment approaches its annual minimum. Accompanying the rapid intensification of the surface winds from March to June (especially the meridional component), the entrainment rate increases dramatically. The mixed layer in the eastern Pacific is shallowest in spring and rapidly deepens with the intensification of the surface winds (Fig. 6d). The maxi- 

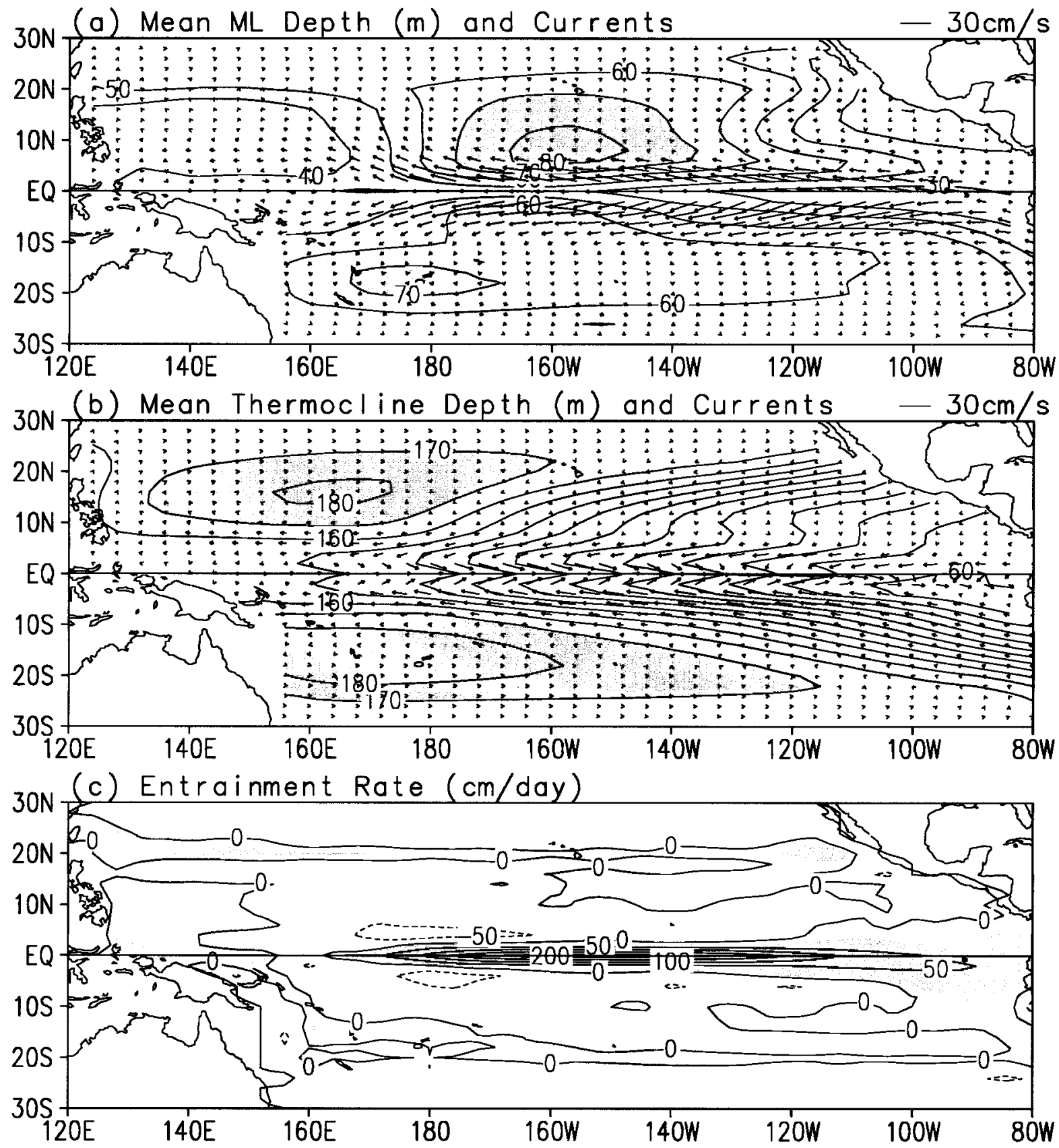

Fig. 4. Simulated annual mean mixed layer depth $(\mathrm{m})$ and $M L$ currents $\left(\mathrm{cm} \mathrm{s}^{-1}\right)(a)$, thermocline depth $(\mathrm{m})$ and the currents $\left(\mathrm{cm} \mathrm{s}^{-1}\right)$ in the thermocline layer (b), and entrainment rate $\left(\mathrm{cm} \mathrm{day}^{-1}\right)(\mathrm{c})$ in the tropical Pacific.

mum entrainment occurs in the central Pacific in fall when surface winds are strongest. In the eastern Pacific it occurs in early summer in agreement with the ocean GCM results of Kessler et al. (1998). This is primarily caused by the shallowness of the ML depth in early summer (Fig. 6d).

Surface heat fluxes are an important factor in regulating annual variations of SST in the tropical Pacific. Figure 7 compares the simulated annual variations of the surface heat fluxes with their observed counterparts derived from COADS by Oberhuber (1988). Because the annual variations of surface longwave radiation and sensible heat fluxes are considerably smaller than the other components, they are not presented. East of $120^{\circ} \mathrm{W}$, the net surface heat flux is dominated by an annual cycle with a maximum (minimum) downward flux in March (July) (Figs. 7a,d). West of $120^{\circ} \mathrm{W}$, a semiannual cycle with two peaks in March and Sep- 
(a) Seosonal Cycle of SST (OBS)

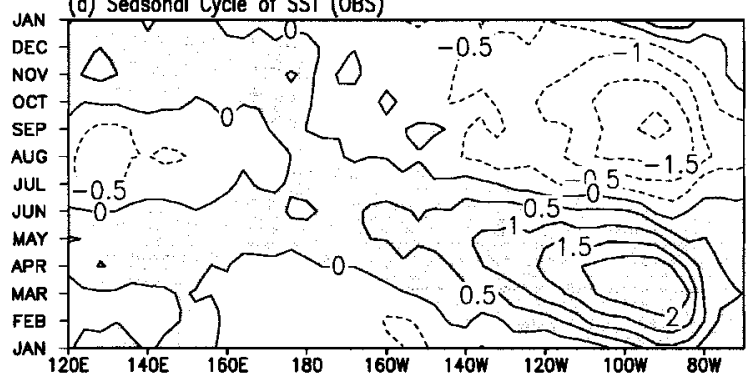

(b) Seasonal Cycle of SST (CTL)

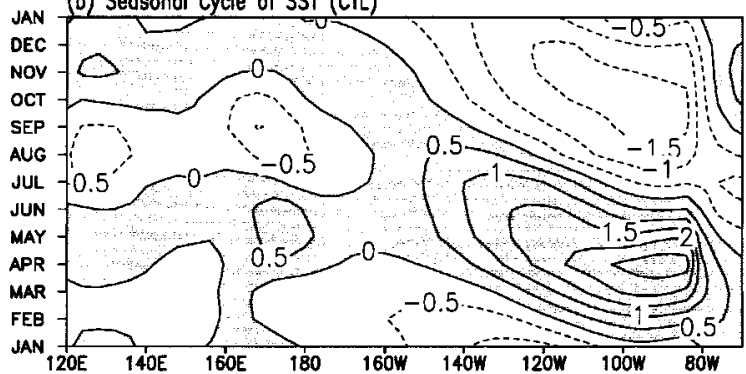

(c) Seosonal Cycle of Zonal Wind (OBS)

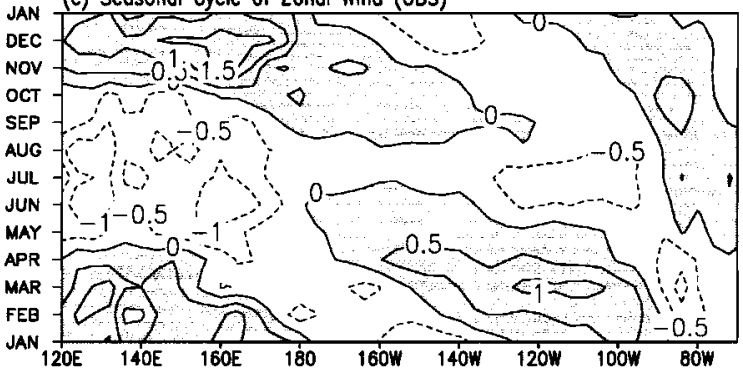

(d) Seasonal Cycle of Zonal Wind (cTL)

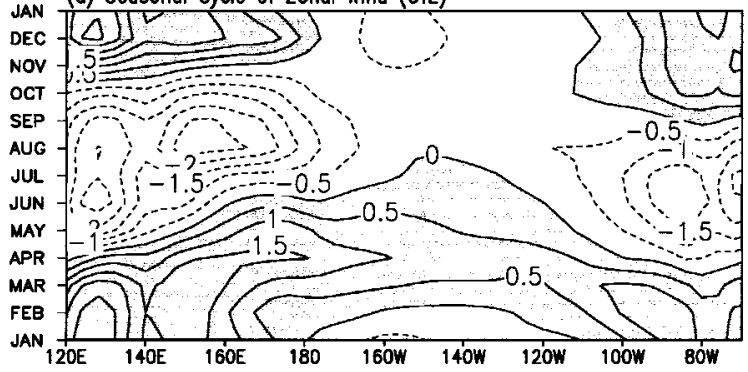

FIG. 5. Time-longitude sections of the demeaned (monthly mean minus annual mean) seasonal cycles in the equatorial Pacific: (a) observed SST, (b) simulated SST, (c) observed zonal wind ( $\left.\mathrm{m} \mathrm{s}^{-1}\right)$, and (d) simulated zonal wind $\left(\mathrm{m} \mathrm{s}^{-1}\right)$.

tember dominates. The simulated annual perturbation of the latent heat flux bears some resemblance to the observations. In the central Pacific, the latent heat flux is smallest in boreal spring (Figs. 7b,e) in accord with the weakest surface winds. In the eastern Pacific, the simulated latent heat flux shows notable discrepancy with the observation. However, since the net surface heat flux is dominated by the solar radiation in this region (Figs. $7 \mathrm{c}, \mathrm{d}$ ), the net surface heat flux compares (a) Seosonal Cycle of ML Zonal Current $(\mathrm{cm} / \mathrm{s})$
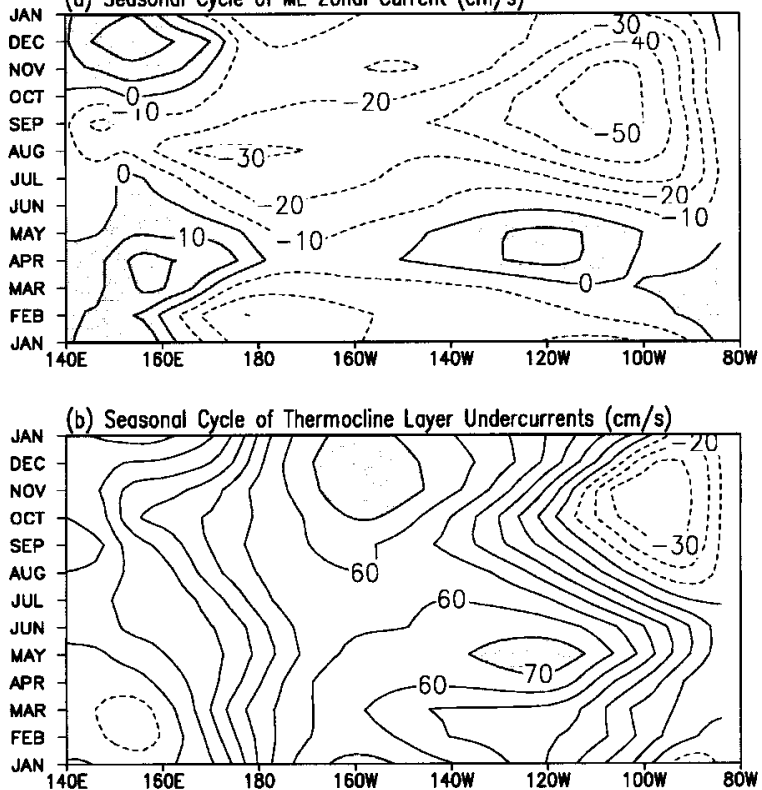

(c) Seasonol Cycle of Entrainment Rate $(\mathrm{cm} / \mathrm{doy})$
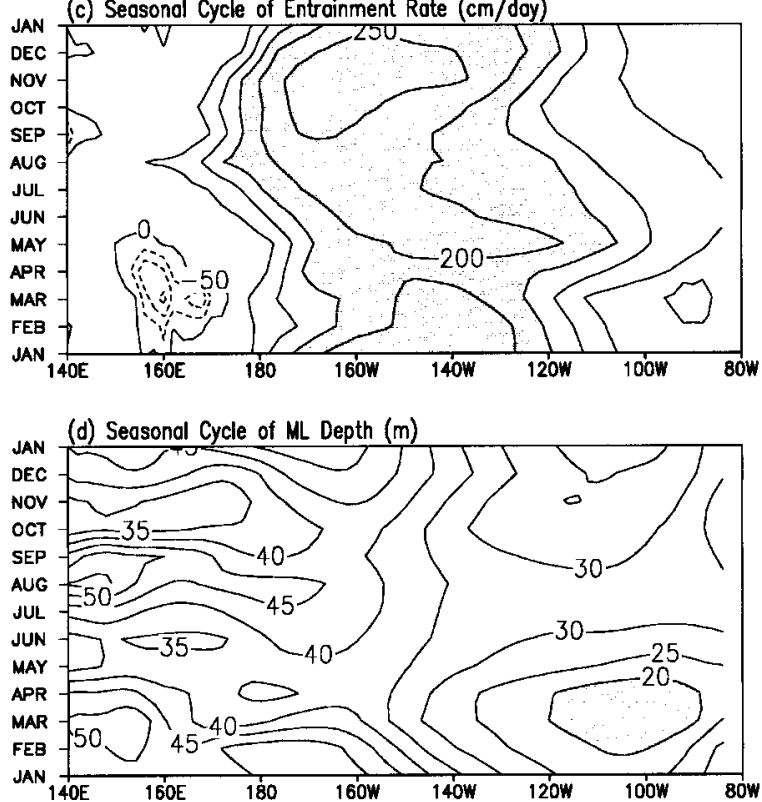

FIG. 6. Simulated annual variations in the equatorial Pacific: (a) zonal currents $\left(\mathrm{cm} \mathrm{s}^{-1}\right)$ in the mixed layer, (b) zonal currents $(\mathrm{cm}$ $\mathrm{s}^{-1}$ ) in the thermocline layer, (c) the entrainment rate $\left(\mathrm{cm} \mathrm{day}^{1}\right)$, and (d) the mixed layer depth $(\mathrm{m})$. The shading highlights maximum regions.

favorably to the observation. Due to the well-known uncertainty of the observed surface heat fluxes (Weare et al. 1981; Oberhuber 1988; and Chen et al. 1994), we are not sure how large the model errors are. More accurate observations over the oceans are needed to check the validity of the model climatology in surface heat fluxes. 
(a) Net Surfoce Heot Flux (COADS)

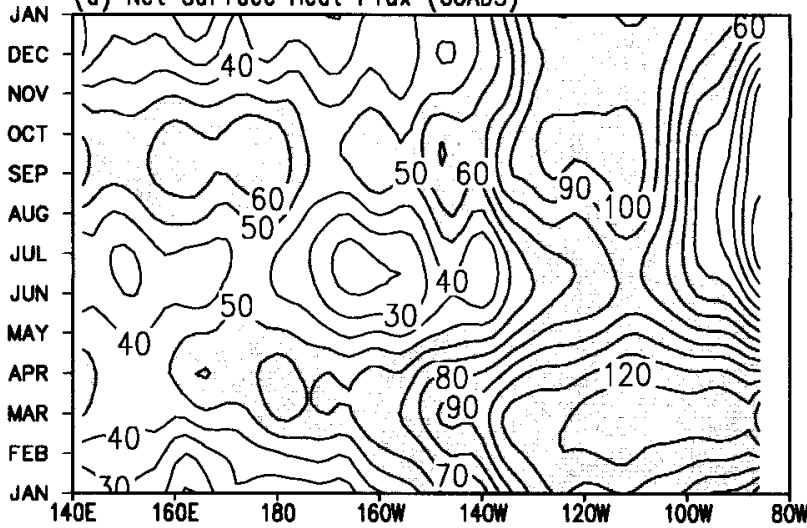

(b) Latent Heat Flux (COADS)
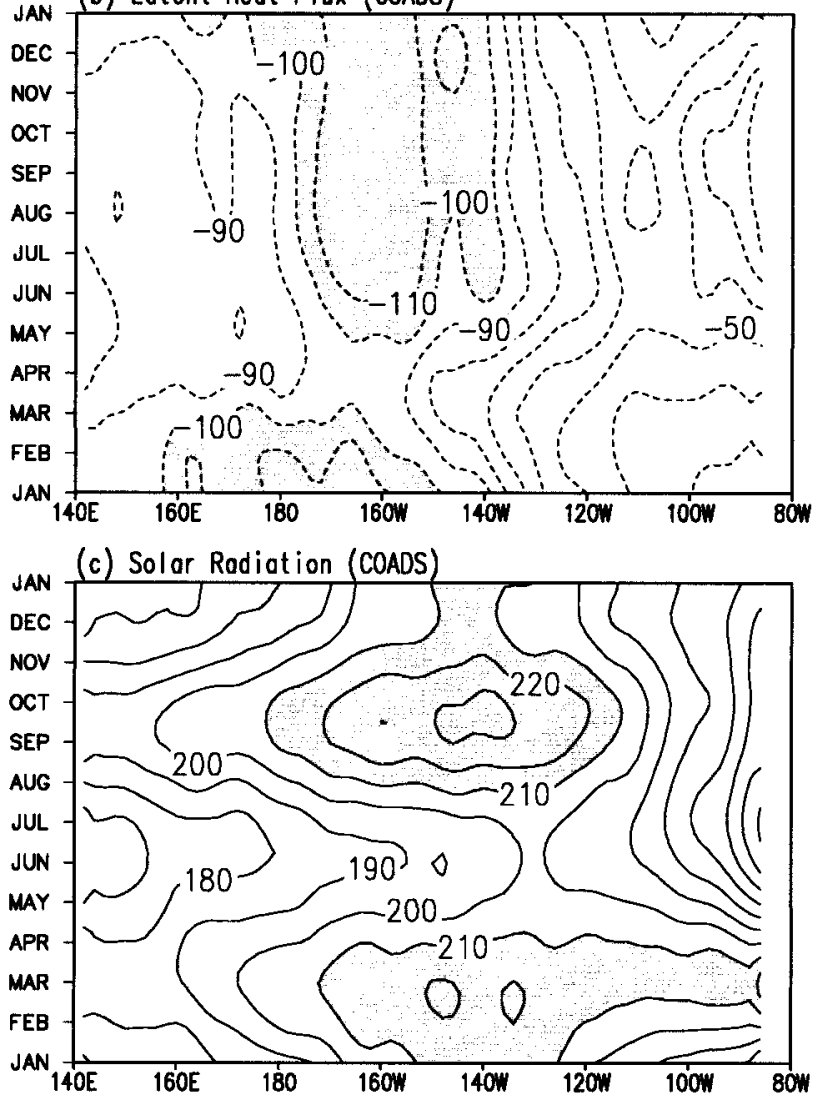

(d) Net Surface Heot Flux (CTL)

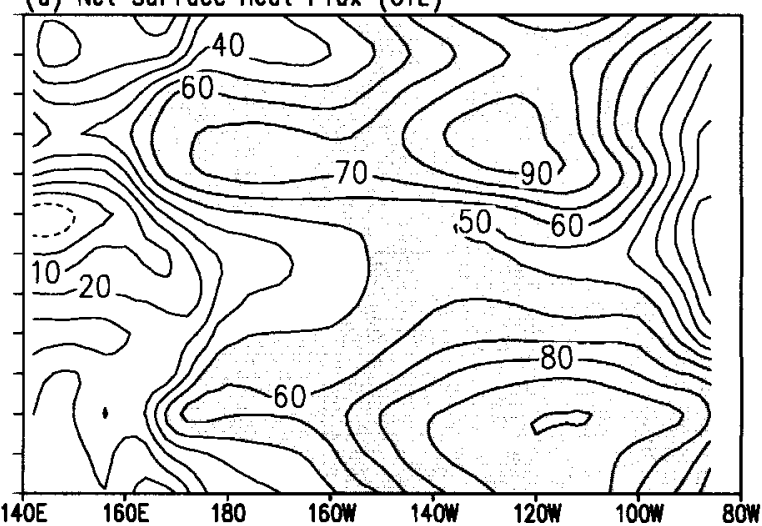

(e) Latent Heat Flux (CTL)

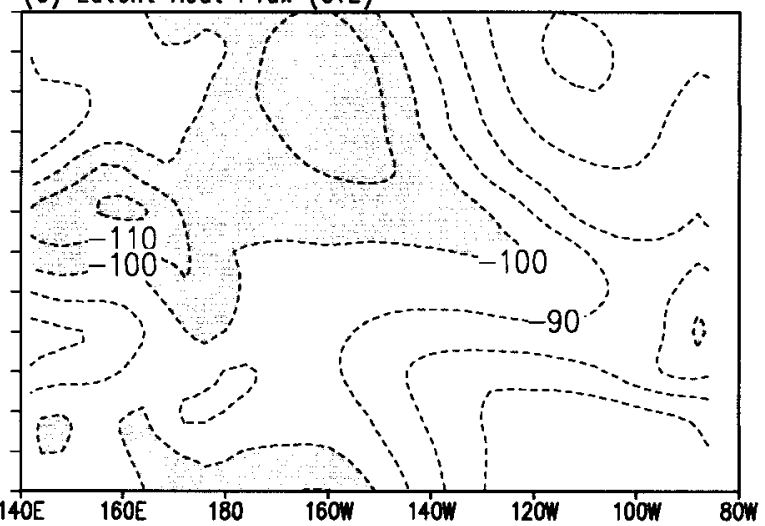

(f) Solar Rodiation (CTL)

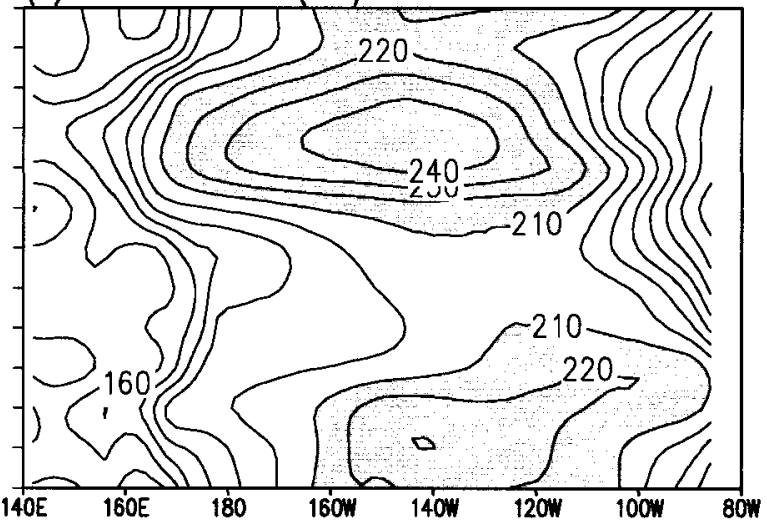

FIG. 7. Observed annual variations of the net downward surface heat flux $\left(\mathrm{W} \mathrm{m}^{-2}\right)$ (a), surface latent heat flux (W m $\left.{ }^{-2}\right)(b)$, surface solar radiation $\left(\mathrm{W} \mathrm{m}^{-2}\right)(\mathrm{c})$, along the equatorial Pacific. The data are derived from COADS (Oberhuber 1988). The three right panels (d), (e), (f) show the model simulated counterparts. The shading highlights regions of interest.

\section{Mechanism of the westward phase propagation} of annual warming

The modeled annual perturbations in the equatorial SST (Fig. 5b) show westward phase propagation similar to the observations. What is responsible for this equatorial westward propagation in this model? In order to answer this question, we present in Fig. 8 the demeaned (monthly mean minus annual mean) ML heat budget along the equator. The heat budget analysis includes the total rate of SST change and the contributions from the net downward heat flux, zonal heat advection, and entrainment, respectively [Eq. (10)]. All tendencies are calculated at every time step (3-h interval) and accumulated for one month, so the transient effects should be included as well. The influences of meridional heat advection and horizontal heat diffusion are primarily 
(a) Rote of SST Chonge (C/mon)

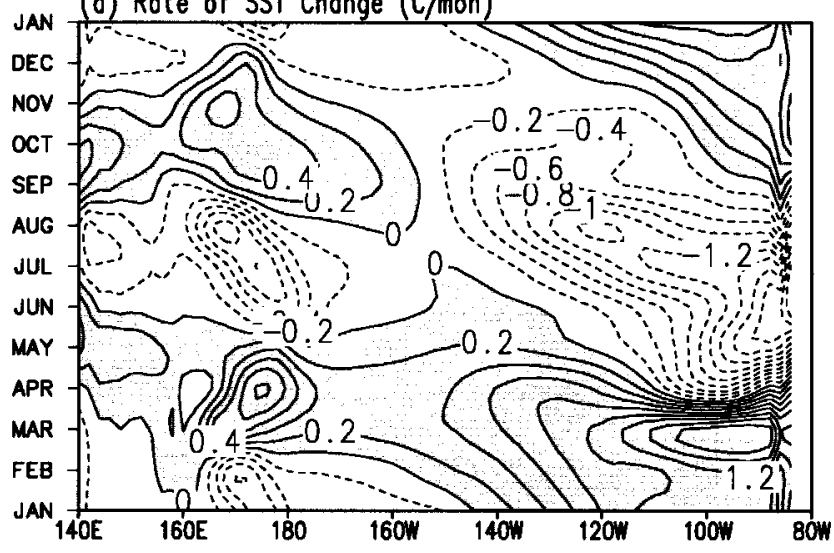

(c) Zonal Advection Term

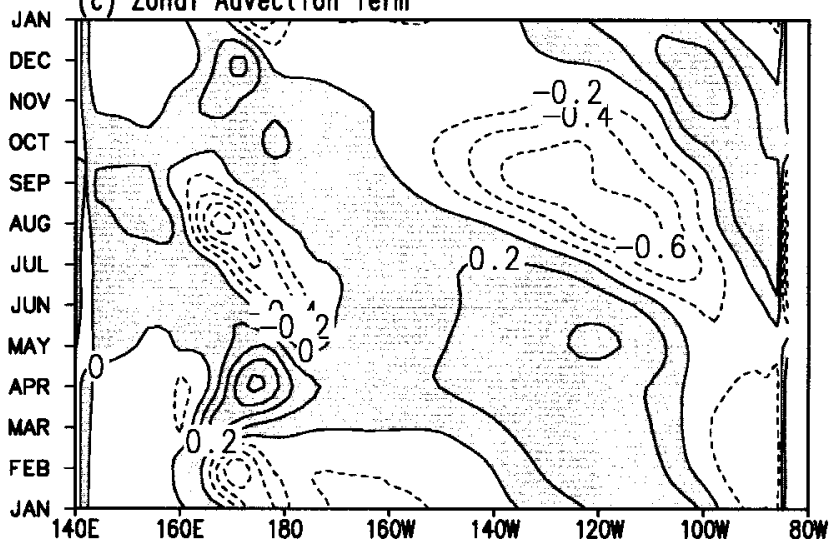

(b) Net Surface Heot Flux Term

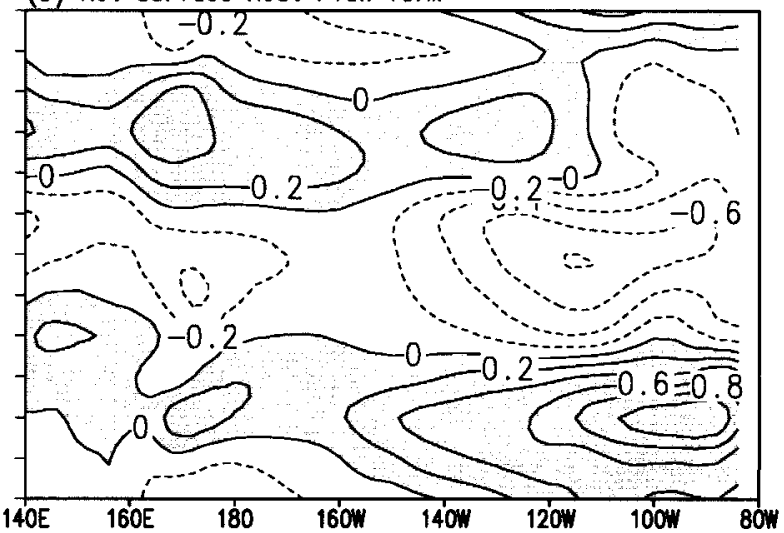

(d) Entraiment Term

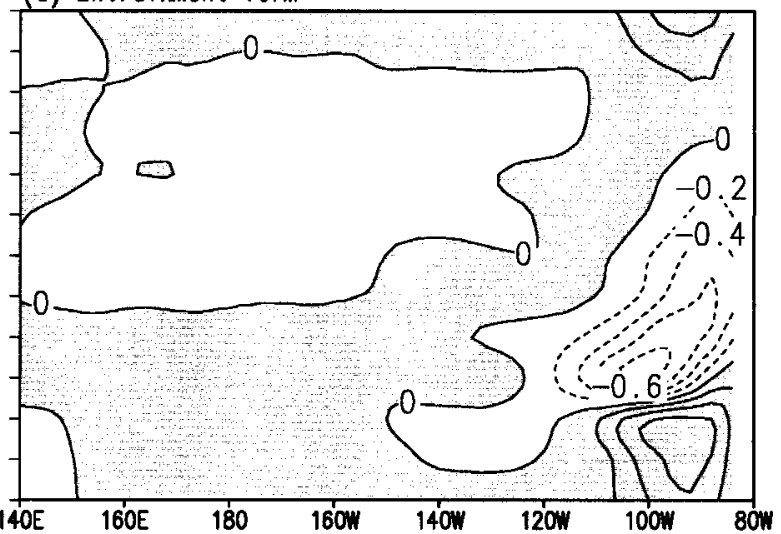

FIG. 8. The demeaned mixed-layer heat budget in the equatorial Pacific computed from the output of the model control run: (a) net rate of change in SST $\left({ }^{\circ} \mathrm{C}\right.$ month $\left.{ }^{-1}\right)$, (b) net surface heat flux term $\left({ }^{\circ} \mathrm{C}\right.$ month $\left.{ }^{-1}\right)$, (c) zonal advection term $\left({ }^{\circ} \mathrm{C}\right.$ month $\left.{ }^{-1}\right)$, and $(\mathrm{d})$ entrainment term $\left({ }^{\circ} \mathrm{C}\right.$ month $\left.^{-1}\right)$.

confined to the eastern equatorial Pacific and have no direct contributions to the westward propagation. Therefore, these terms are excluded.

The net heat flux term shown in Fig. $8 \mathrm{~b}$ reflects the combined effects of the surface heat fluxes, the penetrated solar radiation, and the influence of the ML depth variation [Eq. (10)]. East of $120^{\circ} \mathrm{W}$, an annual cycle dominates the net heat flux with a maximum in March and a minimum in July, primarily due to the annual cycles of the solar radiation and the ML depth. West of $120^{\circ} \mathrm{W}$, a semiannual cycle becomes obvious with two maxima (minima) occurring in March and October (July and December), respectively. If the SST is only determined by the net heat flux, a significant semiannual cycle will be produced west of $120^{\circ} \mathrm{W}$. However, the SST exhibits a dominant annual cycle between $160^{\circ}$ and $120^{\circ} \mathrm{W}$ in both the observations and in the simulation (Figs. 5a,b), suggesting that the net surface heat flux is not a dominant factor in the westward phase propagation of SST. The entrainment effects on the SST annual cycle are basically limited to the eastern Pacific (Fig. 8d) and do not directly contribute to the westward propagation of the SST annual perturbations.
The fact that the above terms are unable to account for the westward propagation suggests that oceanic dynamics play the dominant role. Note that westward propagation is seen in the zonal heat advection term (Fig. $8 \mathrm{c})$. Its effect is stronger in the cold season than in the warm season. However, to the east of $120^{\circ} \mathrm{W}$, the speed of westward propagation of the rate of SST change (Fig. $8 \mathrm{a})$ is faster than what can be explained by zonal heat advection alone. The combined effect of the zonal heat advection and the net heat flux yields a faster westward phase propagation, which agrees with the observation (Fig. 8a). This suggests that the net heat flux (primarily the solar radiation modified by clouds) tends to accelerate the apparent westward phase propagation of the annual warming.

The surface latent heat flux shows a subtle westward signal west of $120^{\circ} \mathrm{W}$ (Figs. 7b,e) which is, however, not critical to the modeled westward propagation of the SST annual cycle. Additional sensitivity experiments indicate that, even with a fixed surface latent heat flux, the westward propagation of the SST annual cycle is almost the same as that in the control run.

In summary, the results of the sensitivity experiments 
Equatorial SST Seasonal Cycle ( $V$ only)

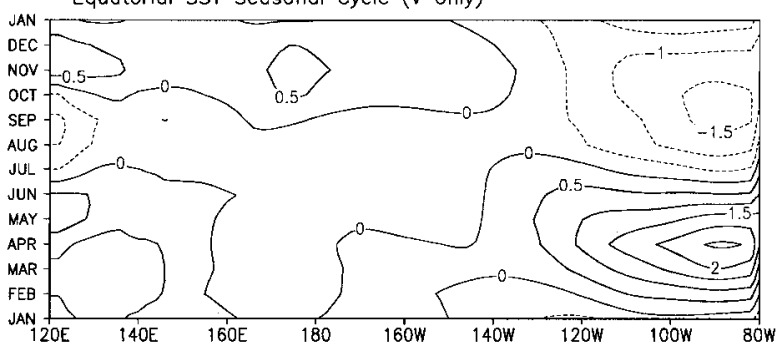

FIG. 9. The demeaned seasonal cycle of SST along the equatorial Pacific simulated in the experiment with the zonal wind component fixed on the annual mean (only allowing the existence of the annual variations of the meridional wind component).

indicate that, in this model, the zonal heat advection is the most important process causing the equatorial westward propagation of the SST annual cycle. To the east of $120^{\circ} \mathrm{W}$, the net downward heat flux along the equator (primarily solar radiation) tends to increase the speed of the westward propagation. The contribution by latent heat flux is negligibly small. The entrainment does not directly contribute to the model's westward propagation of the SST seasonal cycle.

\section{Further sensitivity experiments}

\section{a. Relative importance of the meridional and zonal wind forcing}

In order to identify the relative contribution of the zonal and meridional component of the surface winds on the seasonal cycle of SST in the equatorial Pacific, two sensitivity experiments are conducted. In the first experiment, the model setting is the same as in the control experiment (CTL) except that the zonal wind component was artificially fixed to the annual mean values that are obtained in the CTL experiment. In contrast, in the other experiment the meridional surface wind component was held at the annual mean value. In the previous experiments by Kessler et al. (1998), only the dynamical effects of winds were altered without considering any of the thermodynamic effects of the wind variation. In this study, the change of the individual wind component alters the total wind speed, thereby changing the wind stress, the entrainment, and latent (and sensible) heat fluxes. The sensitivity experiments designed here aim to estimate the impacts of the zonal and meridional wind component on the SST seasonal cycle through both dynamic and thermodynamic processes.

Figure 9 shows the equatorial SST seasonal cycle along the equator for fixed zonal winds. Compared with the control run (Fig. 5b), the SST seasonal cycle is very similar east of $120^{\circ} \mathrm{W}$. However, the areas with SST annual perturbations larger than $0.5^{\circ} \mathrm{C}$ are confined to an area east of $140^{\circ} \mathrm{W}$ in this case. In the observations and control run, the $0.5^{\circ} \mathrm{C}$ contours actually extend far to the west of $140^{\circ} \mathrm{W}$. The result suggests that the sea-
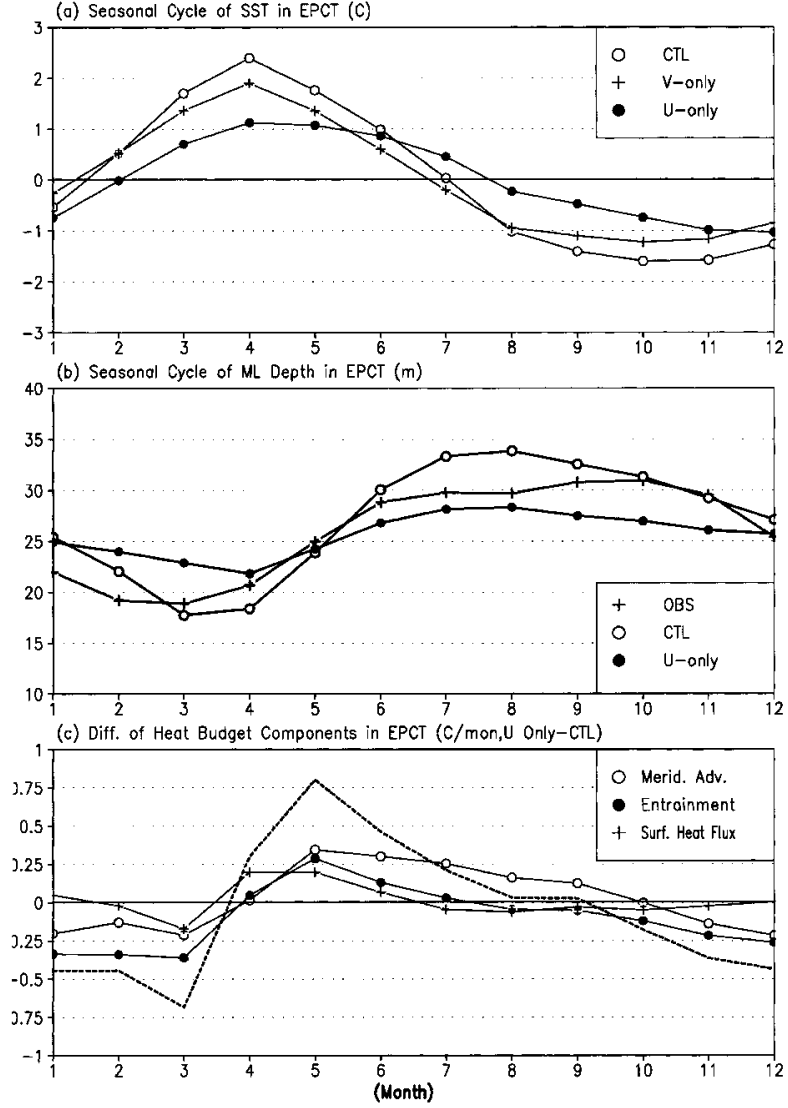

FIG. 10. (a) The demeaned seasonal cycles of SST simulated in the control run (CTL), in the experiment when the zonal wind component is fixed ( $V$-only), and in the experiment in which the meridional wind component is fixed ( $U$-only). (b) The seasonal cycles of ML depth (m) from the observations (OBS) and simulations in CTL and when the meridional wind component is fixed on the annual mean ( $U$-only). (c) The major differences in the mixed-layer heat budget terms $\left({ }^{\circ} \mathrm{C}\right.$ month $\left.{ }^{-1}\right)$ between the fixed meridional wind component ( $U$-only) and CTL, the difference of the net rate of SST change (dash line) and the major contributors: meridional heat advection (empty circle), entrainment (filled circle), and net surface heat flux (cross) in the eastern Pacific cold tongue $\left(4^{\circ} \mathrm{S}-2^{\circ} \mathrm{N}, 120^{\circ}-90^{\circ} \mathrm{W}\right)$.

sonal cycle of zonal wind is important for the equatorial westward propagation of the SST seasonal cycle.

In the absence of annual variations of the zonal wind component, the SST seasonal cycle is similar to that of the control run in the EPCT (Fig. 10a). The difference appears as about $20 \%$ reduction of the annual range. On the other hand, in the absence of the annual variation of the meridional wind component, the resultant amplitude of the SST seasonal cycle is only one-half that in the control run. In addition, the occurrence of the coldest season delays by two months. This suggests that the annual variation of the meridional wind component is more important than the zonal wind component on the SST seasonal cycle in the eastern equatorial Pacific.

Without the annual variation of the meridional wind component, the annual variability of the mixed layer depth is substantially reduced (Fig. 10b). The cooling 
a) Differences of Annual Mean SST (CTL-MCTL)
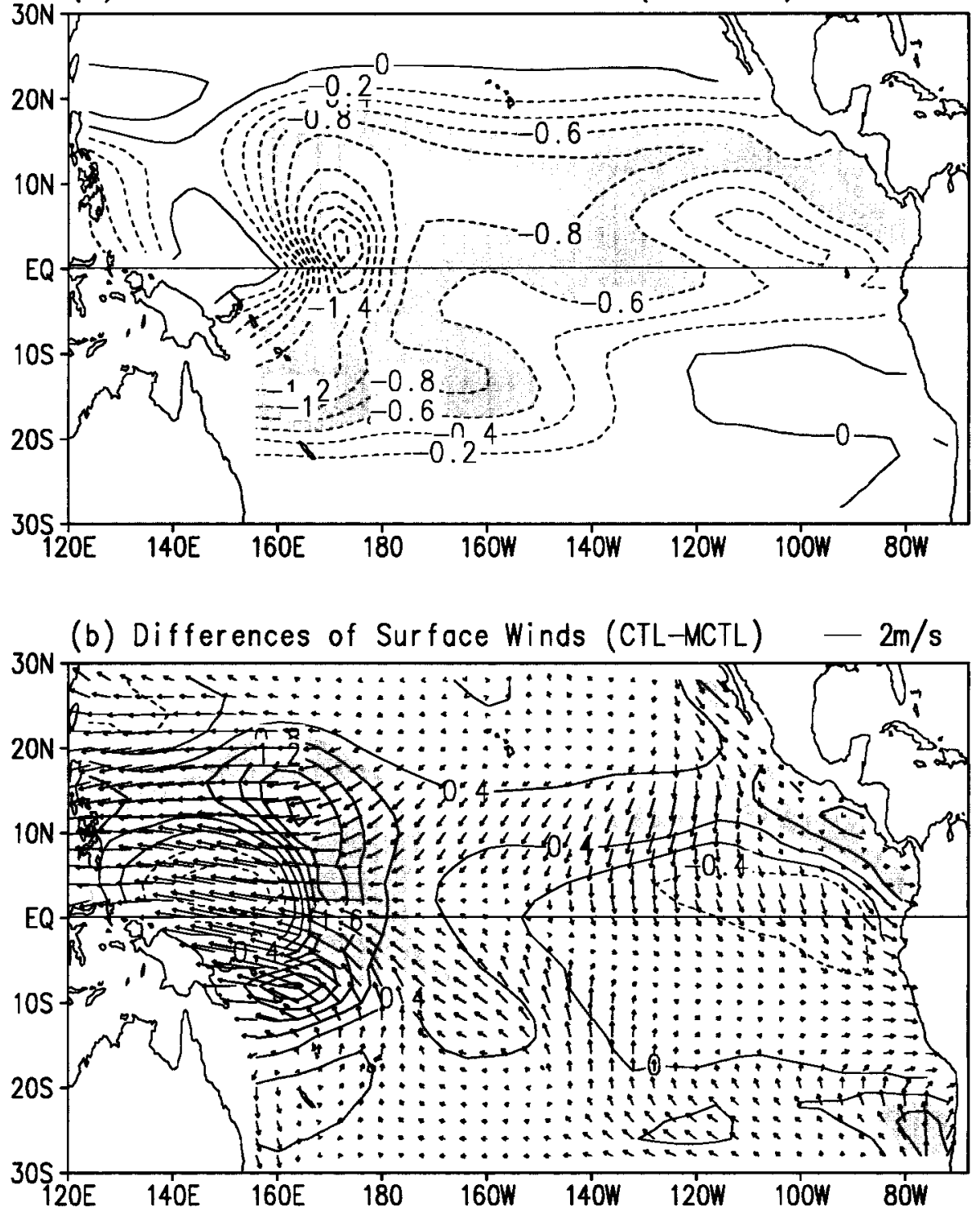

FIG. 11. The long-term mean differences of (a) SST, (b) surface winds between the control run and the case without annually varying solar radiation (CTL - MCTL).

rate due to the changes of entrainment and surface heat flux increases (decreases) in boreal winter-spring (summer) comparing to the control run (Fig. 10c). A northward cross-equatorial cold advection occurs during January and March, instead of the period from April to June in the control run. The contribution of the thermodynamics (entrainment and surface heat flux) to the total perturbation is larger than that of the dynamics (meridional advection). The combined effect due to the changes of entrainment, surface heat flux, and meridional advection is the decrease of the spring (summer) warming (cooling) of the EPCT (Fig. 10c). Therefore, the amplitude of the SST seasonal cycle in this case is considerably reduced. b. Effects of annual variations on the long-term mean state

With a fully coupled model, it is possible to estimate the rectification of the annual cycle to the long-term mean states. For this purpose, we have performed an experiment in which the solar forcing and cloudiness are fixed at the annual mean value so that the annual variations are removed from the integration. All other parameters are the same as those in the control experiment (CTL). For convenience, this experiment will be referred to as MCLT.

Figure 11 shows the differences of the long-term mean SST and surface winds between the control run 


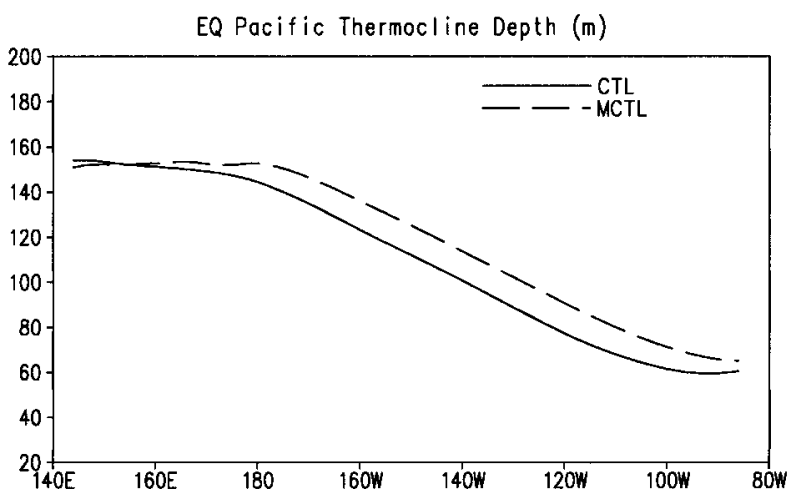

FIG. 12. The long-term mean differences of thermocline depth along the equatorial Pacific between the control run and the case without annually varying solar radiation (CTL - MCTL).

and the experiment without the annual variation of solar radiation (and clouds) (CTL-MCTL). The spatial structures of long-term mean SST (e.g., the warm pool and cold tongue) and the surface winds (trades and convergence zones) in the tropical Pacific can be reproduced without the annual variations of solar radiation. However, with the seasonal varying solar forcing, the tropical Pacific Ocean becomes cooler. The maximum cooling reaches $2^{\circ}$, occurring at the equator and around $170^{\circ} \mathrm{E}$ (Fig. 11a). The decreases in mean SST are generally associated with the increases in the surface wind speeds (Fig. 11b). This suggests that the evaporational cooling associated with increases in wind speed is largely responsible for the cooler SST. On the other hand, in accord with this SST perturbation, the trade winds enhance and the westerly monsoon decreases in the western Pacific (Fig. 11b). Therefore, the change of the mean state also involves air-sea interaction. The result here suggests that the annual cycle forcing tends to cool the tropical Pacific Ocean, specifically causing a westward shift of the western Pacific warm pool. This can be seen from the considerable cooling in the eastern edge of the warm pool. It can also be seen from the thermocline depth variation along the equator (Fig. 12), with the seasonal cycle forcing the steep thermocline slope shifts westward, in accordance with the enhanced easterlies in the western Pacific (Fig. 11b).

In the eastern Pacific, the seasonal cycle forcing cools the ITCZ region more than the equatorial cold tongue, implying that the annual cycle forcing reduces the meridional climate asymmetry (Fig. 11a). Correspondingly, the northward cross-equatorial flows weaken in the presence of the seasonal cycle. The seasonal cycle forcing tends to reduce the mean strength of the ITCZequatorial cold tongue complex and the north-south thermal contrast between the two hemispheres.

\section{Summary and discussion}

The intermediate coupled model described in this paper fills the gaps between the anomaly coupled models and the coupled GCMs. Numerical experiments have demonstrated its capability in realistically reproducing the mean seasonal cycles of SST, surface winds, rainfall, and ML depth and currents in the tropical Pacific. It provides a useful tool for studying the physical processes determining the annual cycle of the coupled ITCZ-EPCT complex.

The westward progression of the annual warming was attributed to a positive feedback between SST gradients and zonal winds through equatorial upwelling by Horel (1982). Using a simple anomaly air-sea coupled model, Xie (1994) posed the wind-entrainment and wind-evaporation feedback as the principal processes for the westward propagation. On the other hand, Chang and Philander (1994) suggested that the zonal advection of SST perturbation by the mean South Equatorial Current is the most important process. The numerical experiments with the present coupled model suggest that the seasonal cycle of the zonal wind component plays a major role in reproducing the westward progression of annual warming. The heat budget study of the model output reveals that zonal heat advection along with the downward solar radiation modified by the clouds is a primary process causing the westward propagation of the SST seasonal cycle. The zonal advection alone cannot explain the rapid westward shift to the east of $120^{\circ} \mathrm{W}$ in both the modeled and observed SST seasonal cycles. The contribution from latent heat flux is small and the entrainment makes no direct contribution to the modeled westward propagation.

For the annual variation of SST in the equatorial eastern Pacific, the meridional wind component plays a more important role than the zonal wind component. In the absence of the annual variation of the zonal wind, the annual warming (from March to June) and the annual cooling (from September to December) are only moderately reduced by about $0.3^{\circ} \mathrm{C}$. In contrast, without the meridional wind variation, the annual range of SST is reduced by one-half $\left(\sim 2^{\circ} \mathrm{C}\right)$. The meridional wind affects SST mainly by changing evaporation, entrainment, meridional advection, and the mixed-layer depth. By fixing the meridional wind, the annual variation of the mixed-layer depth becomes very small.

Most of the simple air-sea coupled models are anomaly models in which the climatological mean states of the atmosphere and ocean are specified. It is not clear how the seasonal cycle impacts the mean state. We have found that the seasonal cycle in the tropical Pacific has a considerable rectification with the long-term mean state. The primary effect of the seasonal cycle on the mean state is a westward shift of the warm pool and a reduction of the latitudinal climate asymmetry in the eastern Pacific. Note that, in our experiments, the cloudiness is specified. This excludes a possible cloud-radiation-SST feedback. The consequence of this limitation cannot be assessed unless a fully coupled model with interactive clouds is used. We defer this to a future study. 
Acknowledgments. This study has been supported by the National Oceanic and Atmospheric Administration (NOAA): Pan-American Climate Study (PACS) and Global Ocean-Atmosphere-Land System (GOALS) programs. This is the School of Ocean Earth Science and Technology Publication Number 5302 and the International Pacific Research Center Publication Number 68.

\section{REFERENCES}

Bjerknes, J., 1969: Atmospheric teleconnection from the equatorial Pacific. Mon. Wea. Rev., 91, 8411-8427.

Chang, P., 1996: The role of the dynamic ocean-atmosphere interactions in the tropical seasonal cycle. J. Climate, 9, 2973-2998.

_, and S. G. Philander, 1994: A coupled ocean-atmosphere instability of relevance to seasonal cycle. J. Atmos. Sci., 51, 36273648.

Chen, D., A. J. Busalacchi, and L. M. Rothstein, 1994: The roles of vertical mixing, solar radiation and wind stress in a model simulation of the sea surface temperature seasonal cycle in the tropical Pacific ocean. J. Geophys. Res., 99, 20 345-20 359.

Fu, X. H., 1998: Simulation of the tropical Pacific annual cycle with an intermediate ocean-atmosphere-land model. Ph.D. thesis, University of Hawaii, 229 pp.

- and B. Wang, 1999: On the role of the longwave radiation and boundary layer thermodynamics in forcing tropical surface winds. J. Climate, 12, 1049-1069.

Gaspar, P., 1988: Modeling the seasonal cycle of the upper ocean. $J$. Phys. Oceanogr., 18, 161-180.

Horel, J. D., 1982: On the annual cycle of the tropical Pacific atmosphere and ocean. Mon. Wea. Rev., 110, 1863-1878.

Kessler, W. S., L. M. Rothstein, and D. Chen, 1998: The annual cycle of SST in the eastern tropical Pacific, diagnosed in an ocean GCM. J. Climate, 11, 777-799.

Li, T., and S. G. H. Philander, 1996: On the annual cycle of the eastern equatorial Pacific. J. Climate, 9, 2986-2997.

Liu, Z. Y., 1996: Modeling equatorial annual cycle with a linear coupled model. J. Climate, 9, 2376-2385.

_ , and S. P. Xie, 1994: Equatorial propagation of coupled air-sea disturbances with application to the annual cycle of the eastern tropical Pacific. J. Atmos. Sci., 51, 3807-3822.

Matsuno, T., 1966: Numerical integration of primitive equation by use of a simulated backward difference method. J. Meteor. Soc. Japan, 44, 76-84.

McCreary, J. P., and Z. J. Yu, 1992: Equatorial dynamics in a 2.5layer model. Progress in Oceanography, Vol. 29, Pergamon, 61132.

Mechoso, C. S., and Coauthors, 1995: The seasonal cycle over the tropical Pacific in coupled ocean-atmosphere General Circulation Models. Mon. Wea. Rev., 123, 2825-2838.

Miller, M. J., and A. J. Thorpe, 1981: Radiational conditions for the lateral boundaries of limited area numerical models. Quart. J. Roy. Meteor. Soc., 107, 615-628.

Mitchell, T. P., and J. M. Wallace, 1992: On the annual cycle in equatorial convection and sea surface temperature. J. Climate, 5, 1140-1156.

Neelin, J. D., and Coauthors, 1992: Tropical air-sea interaction in general circulation models. Climate Dyn., 7, 73-104.
Oberhuber, J. M., 1988: An atlas based on the COADS dataset: The budgets of heat, buoyancy, and turbulent kinetic energy at the surface of the global ocean. Max-Planck-Institut für Meteorologie Rep. No. 15, 20 pp + plates.

Philander, S. G. H., D. Gu, D. Halpern, G. Lambert, N.-C. Lau, T. $\mathrm{Li}$, and R. C. Pacanowski, 1996: Why the ITCZ is mostly north of the equator. J. Climate, 9, 2958-2972.

Reverdin, G., C. Frankignoul, E. Kestenare, and M. J. McPhaden, 1994: Seasonal variability in the surface currents of the equatorial Pacific. J. Geophys. Res., 99, 20 323-20 344.

Reynolds, R. W., 1988: A real-time global sea surface temperature analysis. J. Climate, 1, 75-86.

Robertson, A. W., C.-C. Ma, C. R. Mechoso, and M. Ghil, 1995: Simulation of the tropical Pacific climate with a coupled ocean atmosphere general circulation model. Part I: The seasonal cycle. J. Climate, 8, 1178-1198.

Rossow, W. B., L. C. Garder, P. J. Lu, and A. Walker, 1988: International Satellite Cloud Climatology Project (ISCCP) Documentation of Cloud Data. WMO/TD-No. 266, World Climate research Program (ICSU/WMO), $75 \mathrm{pp}$.

Sadler, J. C., M. A. Lander, A. M. Hori, and L. K. Oda, 1987: Tropical marine climate atlas. Rep. UHMET87-02, Department of Meteorology, University of Hawaii, Honolulu, HI. [Available from Department of Meteorology, HIG350, 2525 Correa Rd., Honolulu, HI 96822.]

Schneider, E. K., Z. Zhu, B. S. Giese, B. Huang, B. D. Kirtman, J. Shukla, J. A. Carton, 1997: Annual cycle and ENSO in a coupled ocean-atmosphere general circulation model. Mon. Wea. Rev., 125, 680-702.

Shuman, F. G., 1957: Numerical methods in weather predication. II. Smoothing and filtering. Mon. Wea. Rev., 85, 3579-3587.

Slingo, A., and J. M. Slingo, 1988: The response of a general circulation model to cloud longwave radiative forcing. Part I: Introduction and initial experiments. Quart. J. Roy. Meteor. Soc., 114, 1027-1062.

Swenson, M. S., and D. V. Hanson, 1999: Tropical Pacific ocean mixed layer heat budget: The Pacific cold tongue. J. Phys. Oceanogr., 13, 1894-1907

Waliser, D. E., N. E. Graham, and C. Gautier, 1993: Comparison of the highly reflective cloud and outgoing longwave radiation datasets for use in estimating tropical deep convection. J. Climate, 6, 331-353

Wang, B., 1994: On the annual cycle in the tropical eastern central Pacific. J. Climate, 7, 1926-1942.

— term climate variations. J. Atmos. Sci., 50, 260-284.

- and Y. Wang, 1999: Dynamics of the ITCZ-Equatorial Cold Tongue Complex and causes of climate asymmetry. J. Climate, 12, 1830-1847.

— pacific ocean. J. Phys. Oceanogr., 25, 1599-1616.

Weare, B. C., T. Strub, and M. D. Samuel, 1981: Annual mean surface heat fluxes in the tropical Pacific ocean. J. Phys. Oceanogr., 11, 705-717.

Wyrtki, K., 1965: The annual and semiannual variation of SST in the North Pacific Ocean. Limnol. Oceanogr., 10, 307-313.

Xie, S. P., 1994: On the genesis of the equatorial annual cycle. $J$. Climate, 7, 2008-2013.

Yu, J. Y., and C. R. Mechoso, 1999: Links between annual variations of Peruvian stratocumulus clouds and of SST in the eastern equatorial Pacific. J. Climate, 12, 3305-3318. 